\title{
Creative thinking method of foreign language learning at a non-linguistic university
}

\author{
Stanislav Leonidovich Bukovsky ${ }^{*}$ \\ Russian State Agrarian University - Moscow Timiryazev Agricultural Academy, Department of \\ Foreign and Russian Languages, Moscow, Russia
}

\begin{abstract}
This article is devoted to the analysis and development of a creative method and creative techniques for teaching a foreign language at a non-linguistic university. The study aims to develop a methodological basis for the technological way of teaching foreign languages at a non-linguistic university. The author presents definitions of the notions and concepts of creative teaching, functions, and techniques of teaching foreign languages at a non-linguistic university. The article presents the theory and practice of a creative method of foreign language learning, including a detailed analysis of the principles and concept basis and techniques of the given method. The results of the experimental scientific research are presented and can be used in speaking lessons at non-linguistic universities. The paper provides a detailed analysis of the theory of the given method in the form of didactical and methodical principles of foreign language learning, its structure, aims, and content, and also an algorithm of learning techniques. Therefore, there is a description of creative thinking as a didactical and methodical basis of foreign language learning and particularly speaking learning. The article also presents the diversity of appropriate exercises, comprising both creative thinking drills and communicative tasks, making it possible to develop communicative skills at a non-linguistic university.
\end{abstract}

Keywords: speaking, creativity, creative techniques, logic, communicative competence

\section{Introduction}

The article aims to intensify foreign language speaking learning at non-linguistic universities through the introduction, development, and materialization of the innovative approach, based on the creative thinking-oriented method for foreign language speaking learning.

The relevance of this article is determined by the need for innovation in the foreign language learning process with the theoretical and practical integration of creative thinking and the theoretically developed creative thinking-oriented approach for foreign language speaking learning.

*Corresponding author: linguist.method@mail.ru 
The scientific novelty of the research includes the introduction and development of a creative thinking-oriented approach to foreign language speaking learning with the aim of its intensification. This learning approach is generally based on the combination of creative thinking integration into the foreign language learning sphere as a means and technique, forming a new foreign language learning approach at non-linguistic universities.

The scientifically applied meaning of this research is determined by the possibility for practical use of a creative thinking-oriented approach to foreign language speaking learning.

\section{$2 \quad$ Methods}

It should be noted that human thinking is not only the ability of cognitive function activity but also the ability to find better ways for problem-solving connected with novelty and originality [1].

According to Utemov, creative thinking pedagogy is, on the one hand, a scientific sphere of the multidisciplined area of scientific activity, which is closely connected with pedagogy, educational psychology, and foreign language learning. On the other hand, creative thinking is an independent area of pedagogical science [2].

Therefore, the author of this paper developed the following algorithm of the foreign language learning process based on six stages:

\subsection{The first stage - creative comprehension determination}

This stage aims to make students realize and understand creative thinking itself and its necessity in the learning process. This stage is the lead-in of a foreign language lesson. In this stage, a teacher formulates the aim and tasks of the lesson. Since the first minutes of the lesson, students must be involved in the creatively oriented learning activity. This stage comprises preparation and determination of students' comprehension for creative learning conditions. The length of this stage is about 2-3 minutes at the beginning of the lesson.

\subsection{The second stage - knowledge learning}

This stage focuses on the presentation by a teacher of new lexical and grammatical material. This stage aims to inform students on new material and to modify this information into knowledge while using creatively oriented methods of presenting new material by a teacher. The length of this stage is about 10 minutes.

\subsection{The third stage - creative learning pause}

This stage demonstrates the students' analysis of information received during the lesson. Implementation of this stage includes a so-called creative pause to analyze the theoretical material. After the presentation stage, the teacher announces a creative pause which means a silent analysis period when students try to analyze the presented information for its further implementation and use during the lesson at the controlled and production stages. The length of this stage is about 2-3 minutes. 


\subsection{The fourth stage - controlled stage}

It is the stage of using guided, controlled practice activities - lexical and grammatical drills. These drills are creatively oriented exercises aimed at improving the knowledge of the lexical and grammatical material. During this stage, students make creatively oriented lexical and grammatical drills in a form of gap-filling, jigsaw activities, odd one out, rephrasing, completion, and expansion. The length of this stage is 20-25 minutes.

Examples of the exercises:

1. Find as many definitions for the following words as you can.

For example: wheat - winter wheat.

2. Give the answers defining the following words.

Example: command, market, mixed-economy.

3. Make your own sentences based on words, in which every word begins with the following letters:

Example: D...A...S...-Demand And Supply.

\subsection{The fifth stage - production stage}

This stage is the general for the lesson as a whole and takes a large part of it. The aim of this stage is the development of communicative skills in a form of brainstorming, presentation, discussion, oral report, problem-solving, role play, project work, and description.

An example of the exercise:

In Figure 1 the surreal situation is shown: clouds are attached with cords hanging down to the ground. What can happen in this situation? Give as many variants as you can.

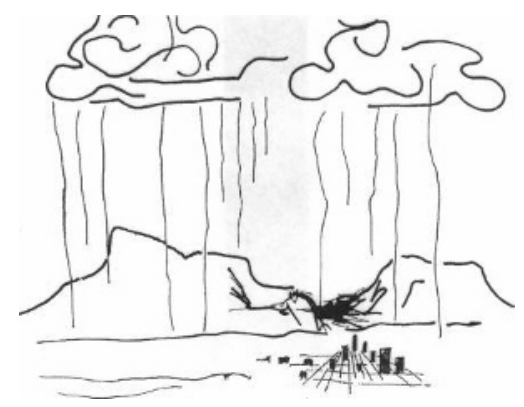

Fig. 1. Surreal situation.

\subsection{The sixth stage - reflective conclusion}

This stage is the end of the lesson implying a conclusion in a form of completing self-estimation and self-analysis progress cards by students with the aim of self-analysis of their progress and academic results.

\section{$3 \quad$ Results}


Before the experiment, students of the experimental group were given necessary instructions concerning the aim of the experiment and the ways of its achieving during the interview.

The total number of students participating in the experiment was 120 people. The conditions for experimental research were the time (4 hours in a week, 10 weeks in general with duration of 20-25 minutes).

The learning material for the experimental research included textbooks and a system of exercises with specific creative-oriented content.

Experiential training included 6 stages:

- organization and implementation of a pre-experimental section;

- an introductory conversation about the goals and objectives of experiential learning;

- actual experience training;

- post-experimental section in order to establish the effectiveness of the proposed technique;

- analysis of the results of experimental training.

The results, expressed as a percentage, were approximately equal in both groups, as reflected in Figure 2.

Based on the diagram with the results obtained, where $\boldsymbol{C} \boldsymbol{G}$ is the control group and $\boldsymbol{E} \boldsymbol{G}$ is the experimental group, it can be concluded that there is a rather low level of formation of communicative competence skills.

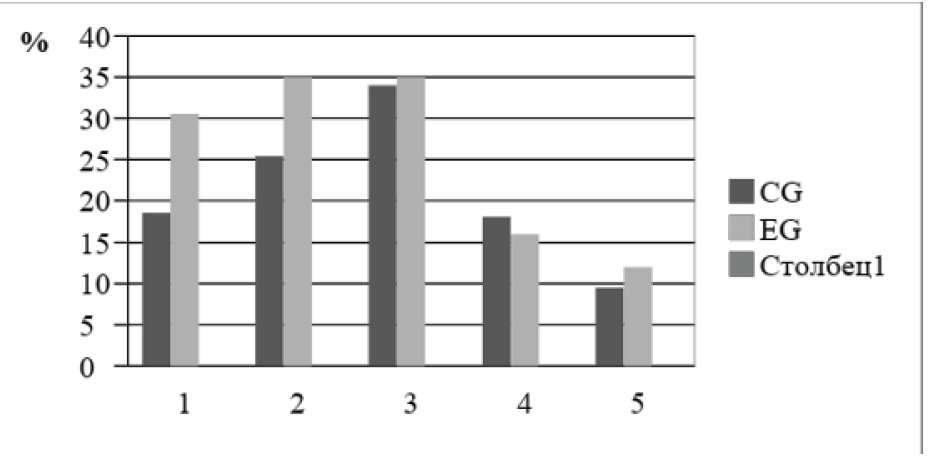

Fig. 1. Results of the pre-experimental section.

The pre-experimental section was followed by an introductory conversation with the subjects of the experimental group.

In the other group (control group - $\boldsymbol{C G}$ ), students were trained in the usual mode based on teaching aids.

To assess the effectiveness of training, the following formula was used:

$$
C=\frac{F 1+F 2+O}{3}
$$

where $\mathrm{C}$ - creativity (creative thinking), F1 - fluency, F2 - flexibility, $\mathrm{O}$ - originality.

Experimental learning was based on a comparison of learning outcomes in the experimental and control groups. Experimental learning aimed to increase the effectiveness of teaching oral communication to future bachelors of an economic university.

Based on the post-experimental section results in Figure 2, one can see the dynamics of changes that were outlined in the course of teaching students oral communication in the 
process of developing creative thinking, where the exercises of the proposed methodology were used as a teaching tool.

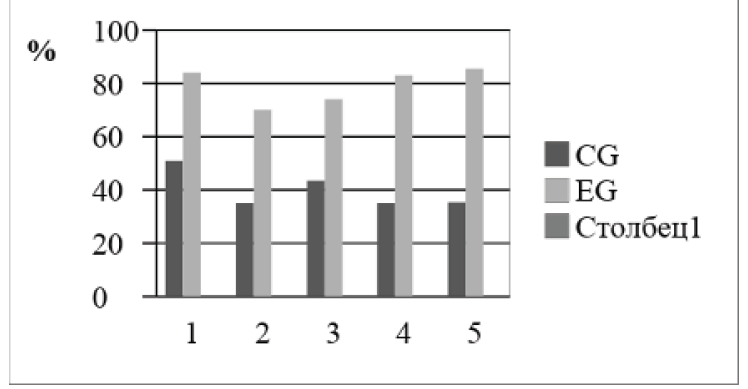

Fig. 2. Post-experimental section results.

\section{Discussion}

According to de Bono, under logical thinking, making a mistake is impossible and even absolutely prohibited because a mistake at any level leads to negative results, distorting logical understanding. Creative thinking is acceptable for unassisted information research activities made on purpose [3].

According to Gilford, there are 16 intellectual abilities, characterizing creativity. The most important from those are fluent thought, the flexibility of thought, and originality [4, $5]$.

Torrance [6] states that creative abilities exist independently from the intellect. Creative abilities, according to that theory, start functioning after achieving a definite intellectual level.

Also, Torrance states that creative thinking is connected with comprehension of critical disadvantages, lack of knowledge, and disharmony [7, 8].

According to Maslow, creativity is determined by its cognitive uniqueness, motivation, values, sensibility to the problem, acting independence in the situation of inevitability for making choice [9].

Many scientists also offer some creative environments for achieving better results from learners. In that sense, Davies et al. offer to use even outdoor environments such as forest schools; a creative environment can include:

- Use of a local woodland setting.

- Regular, frequent contact in the same setting over a significant period of time.

- $\quad$ Providing freedom to explore using multiple senses and intelligence.

- $\quad$ Time and space for individual learning styles to be recognized and nurtured [10].

The experiment carried out by Bereczki and Kárpáti showed that teachers conceptualized creativity through addressing its chief components: process, product, person, and environment [11].

The identical results of the creative environment can be observed in the research of preschool education made by Cansu Yildiz and Tulin Guler Yildiz. The result of their research reveals that the high quality of the home environment makes a positive difference in children's creative thinking skills [12].

Other scientists focus on the interaction between a teacher and students. For instance, Kupers and van Dijk state that only if one studies the interactions between teachers and 
students more closely both qualitatively and quantitatively, one is able to distill what types of interactions foster or hinder creativity [13].

Hooijdonk et al., besides creative fluency and originality, also add completeness and practicality in fact-finding and problem-finding [14].

According to Dekker, researchers should pay attention to multidisciplinary, multiple perspectives, and multiplicity as crucial factors of students' creativity development [15].

Taking into consideration the abovementioned information, one may conclude the advantage of creative thinking over logic, demonstrating the differences between logical and creative thinking in the following Figure 3.

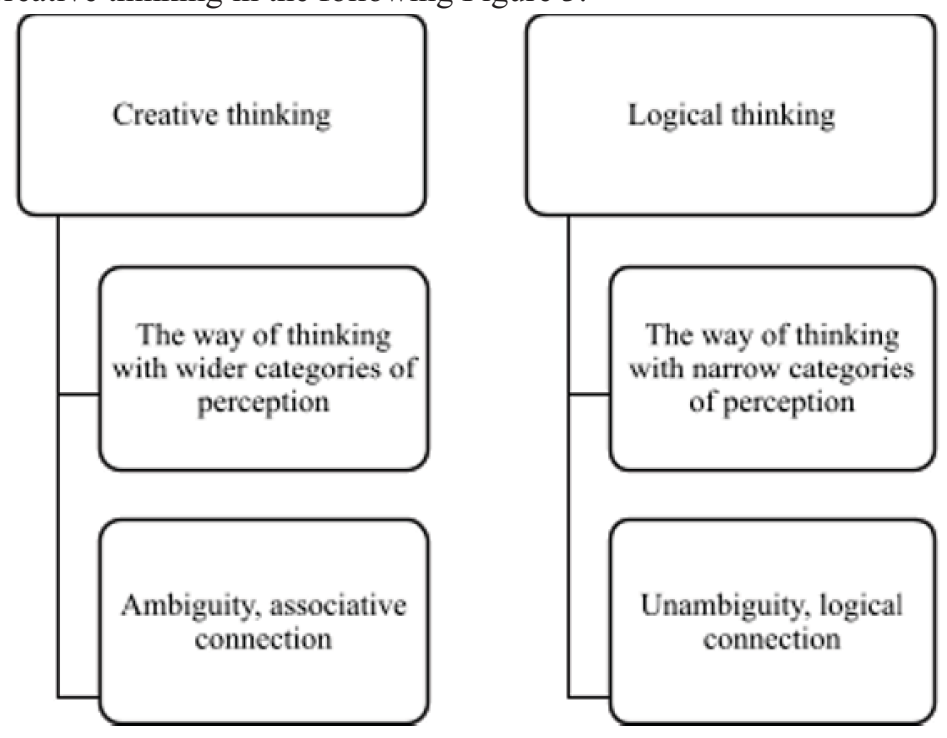

Fig. 3. Differences between creative and logical thinking.

As one can see in Figure 3, creative thinking comprises the ability to think in a way of wider thinking categories, taking into consideration the ambiguity and diversity of all notions and phenomena, using comparison and association connection between them during learning.

\section{Conclusion}

In conclusion, it should be noted that this way of thinking and its realization conditions in the learning process include self-analysis, freedom of choice, an extraordinary way of problem-solving, and non-conformism. The elements, which creative thinking consists of, are fluency, flexibility, and originality of thinking. These elements are also the indicators of testing while making communicative exercises.

Thus, it can be concluded that this scientific issue has the opportunity for further scientific research and analysis in such spheres as psychology, pedagogy, and foreign language teaching. The results of this research show the capacity to make some further scientific investigation in order to develop that topic of scientific discussion.

\section{References}


1. A.V. Matushkin, Myshlenie kak reshenie problemnoi situatsii [Thinking as Problem Situation Solution] (International Communication Publisher, Moscow, 2017)

2. V.V. Utemov, Pedagogika tvorcheskogo myshleniya [Creative Thinking Pedagogy] (Urite Publisher House, Moscow, 2019)

3. de Bono E. Shest shlyap myshleniya [The six hats of thinking] (Piter Publishing, St. Petersburg, 1997)

4. J.P. Gilford, The Nature of Human Intelligence (McGraw-Hill, 1967).

5. L. Guilford, R. Hoepfher, The analysis of intelligence (McGraw-Hill Book Co, New-York, 1971)

6. E.P. Torrance, The nature of creativity as manifest in its testing, in R.W. Sternberg (ed), The nature of creativity (Cambridge, New York, 1965)

7. E.P. Torrance, R.E. Myers, Creative learning and teaching (Mead and Company, New York, 1970)

8. E.P. Torrance, Torrance tests of creative thinking (Personal Press, 1983)

9. A.N. Maslow, Motivation and personality, XIV, C.N.Y. Murphy (ed) (Harper \& Row,Publishers 1954)

10. D. Davies, et al., Think Skills Creativ, 8, 80-91 (2013). https://doi.org/10.1016/j.tsc.2012.07.004

11. E.O. Bereczki, A. Kárpáti, Think Skills Creativ, 39, 100791 (2021). https://doi.org/10.1016/j.tsc.2021.100791

12. C. Yildiz, T.G. Yildiz, Think Skills Creativ, 39, 100795 (2021). https://doi.org/10.1016/j.tsc.2021.100795

13. E. Kupers, M. van Dijk, Think Skills Creativ, 36, 100648 (2020). https://doi.org/10.1016/j.tsc.2020.100648

14. M. Hooijdonk, et al., Think Skills Creativ, 37, 100665 (2020). https://doi.org/10.1016/j.tsc.2020.100665

15. T.J. Dekker, Think Skills Creativ, 37, 100701 (2020). https://doi.org/10.1016/j.tsc.2020.100701 